\title{
A sintaxe do destacamento como elemento discursivo da contemporaneidade
}

DOI: http://dx.doi.org/10.21165/el.v49i3.2472

\section{Érika de Moraes ${ }^{1}$}

\section{Resumo}

O desenvolvimento das tecnologias traz novos questionamentos sobre a interação com a linguagem e, ao mesmo tempo, permite discutir formas inovadoras de compreensão do texto escrito em nosso século, para além da previsão simplista sobre sua morte. Nesse sentido, o conceito de destacamento proposto por Maingueneau, concebido no quadro teórico-metodológico da Análise do Discurso francesa (AD), constitui uma pista fundamental sobre o funcionamento da discursividade contemporânea, uma vez que elementos destacados adquirem especial visibilidade na era da comunicação digital. Daí propormos falar em uma sintaxe do destacamento que considere, na prática, um novo modo de leitura a partir da costura de elementos como títulos, subtítulos, legendas e demais destaques. No presente texto, valorizamos a relação entre o destacamento e a memória discursiva, considerando ainda a noção de competência discursiva (Maingueneau), que recebe um refinamento a partir do trabalho de Mussalim (2018).

Palavras-chave: destacamento; memória discursiva; competência discursiva; contemporaneidade.

1 Universidade Estadual Paulista "Júlio de Mesquita Filho" (UNESP), Bauru, São Paulo, Brasil; erika.moraes@unesp.br; http://orcid.org/0000-0002-6571-3971 


\title{
The syntax of detachment as a discursive element of contemporaneity
}

\begin{abstract}
The development of technologies brings new questions about the interaction with language and, at the same time, allows us to discuss innovative ways of understanding the written text in our century, beyond the simplistic prediction about its death. In this sense, the concept of detachment proposed by Maingueneau, conceived in the theoretical-methodological framework of the French Discourse Analysis (AD), constitutes a fundamental clue about the functioning of contemporary discursivity, since detached elements acquire special visibility in the age of digital communication. Hence we propose to speak about a syntax of detachment that considers, in practice, a new way of reading from the sewing of elements such as titles, subtitles, photo captions and other detachments. In the present text, we value the relationship between detachment and discursive memory, also considering the notion of discursive competence (Maingueneau), which receives a refinement with the work of Mussalim (2018).
\end{abstract}

Keywords: detachment; discursive memory; discursive competence; contemporaneity.

\section{Introdução}

O desenvolvimento das tecnologias tem servido de argumento para se falar do império da comunicação digital, cenário no qual textos escritos supostamente vêm perdendo espaço para formatos multimidiáticos. Em contrapartida, sabe-se que, historicamente, não foram concretizadas as previsões de supressão de um meio de comunicação por outro (o impresso pelo rádio, o rádio pela televisão etc.), mas houve a convivência desses meios, o que ocorre em proporções maximizadas na era da internet, já que a própria linguagem digital se constitui pela apropriação em convergência e ressignificação das outras linguagens. Como expressa Wolf (2019, p. 11), há mais complexidade na "passagem de uma cultura baseada no letramento para uma cultura digital".

Em relação ao jornalismo, pode-se ponderar que, ao contrário de substituir o impresso, as mídias digitais permitiram a sua revalorização como mídia de atualidade instantânea, com o advento dos jornais on-line. É o que defende a autora francesa Ringoot (2014), para quem a imprensa reconquista um status outrora perdido para os meios audiovisuais (o imediatismo, alcançado com a possibilidade de atualizar conteúdos on-line e ser reposicionada como "imprensa quente") e ainda reforça o seu status anterior, o de aprofundamento, aspecto em que sempre foi soberana.

Tal abordagem permite discutir formas inovadoras de compreensão do texto escrito em nosso século, para além da previsão simplista sobre sua morte. Nesse sentido, o conceito de destacamento proposto por Maingueneau $(2006,2014)$, concebido no quadro teórico- 
metodológico da Análise do Discurso francesa (AD), constitui uma pista fundamental sobre o funcionamento da discursividade contemporânea, uma vez que elementos destacados adquirem especial visibilidade na era da comunicação em convergência. Esse cenário nos levou à proposta de compreender a interação com o texto por meio de uma sintaxe do destacamento, que leve em consideração, na prática, um novo modo de leitura a partir da costura de elementos como títulos, subtítulos, legendas e demais destaques.

Ainda conforme Ringoot (2014), a paginação de um jornal, seja em suporte de papel ou desmaterializada na web, delimita uma cena de enunciação. Nossa proposta é apresentar pontos nodais do funcionamento material da sintaxe do destacamento, tomando como dados notícias que circulam em aplicativos como os do jornal Le Monde e BBC News, com o respaldo teórico-metodológico da Análise do Discurso de linha francesa, mais especificamente com base em conceitos propostos por Dominique Maingueneau, como o de destacamento e competência discursiva.

Temos desenvolvido esse estudo em pesquisa mais geral, cujos resultados já apresentamos em alguns trabalhos (MORAES, 2018, 2019a, 2019b). No presente artigo, buscamos, à luz de novos exemplos, empreender uma contribuição teórica no sentido de demonstrar que o destacamento é uma característica inexorável da discursividade contemporânea e interfere na produção de memória discursiva, que se torna mais fragmentada. Buscamos, assim, contribuir para a constante reflexão em torno do abrangente conceito de memória discursiva. No decorrer de nossa pesquisa, tomamos contato com a possibilidade de conciliação entre uma dimensão discursiva da cognição e uma dimensão cognitiva do discurso (MUSSALIM, 2018), o que trouxe novos parâmetros para a nossa compreensão de memória. Conforme abordaremos na seção seguinte, essa possibilidade impactou a relação que buscamos estabelecer entre destacamento e memória, ainda em fase de elaboração, cujas reflexões iniciais gostaríamos de apresentar, como um caminho para avançar nos estudos que empreendemos sobre o destacamento e a produção de efeitos de sentido.

\section{Quadro teórico-metodológico: destacamento, memória discursiva e competência discursiva}

Maingueneau (2006) apresentou a noção de citação e destacabilidade de forma conjunta, elaborando uma reflexão sobre procedimentos, em especial, dos aparelhos midiáticos, que levam ao destaque (por meio da citação) enunciados que já têm a propensão da destacabilidade, ou seja, que funcionam como fórmulas autônomas, já nascem como se fossem memoráveis e facilmente memorizáveis. Em jornalismo, a posição tipograficamente realçada (títulos, subtítulos, legendas) contribui para que determinados aspectos dos acontecimentos noticiados sejam alçados à condição do que é memorável/ memorizável. 
Há destacamento forte, que adquire o estatuto de fórmulas, outros mais fracos, que aparentemente "apenas" cumprem sua função na edição/apresentação do texto jornalístico. Se considerarmos, porém, as características da sociedade contemporânea, mediada pelo excesso de informação, torna-se relevante defender que o destacamento não seja tão somente um dos elementos do texto, mas o ponto nodal de processamento de memória discursiva, sobretudo se tomamos como topografia um ponto da história da humanidade em que as leituras são mais fragmentadas do que profundas².

No desenvolvimento teórico de seus conceitos - sobretudo, com a obra Frases sem texto (2012) -, Maingueneau demonstra, cada vez mais, que o processo da destacabilidade ao destacamento é ainda mais profundo, levando à aforização, quando partes de textos adquirem estatuto de textos próprios, inteiros e conclusos. Paradoxo inevitável: se nem mesmo um texto é completo (sempre atrelado ao interdiscurso), o destacamento o é ainda menos; trata-se, portanto, sempre de construções discursivas. Sabemos, no entanto, que os discursos circulam como uma espécie de "ilusão necessária"3 da completude. Podese dizer que os destacamentos jornalísticos fazem parte do que o autor define como "enunciação aforizante". Esse tipo de enunciação, as ditas "frases sem texto", "têm um funcionamento tal que mantêm com o texto uma relação tensa, como se quisessem saltar para fora dele - e consequentemente, também das condições de produção" (POSSENTI, 2014, p. 8).

O papel dessa relação tensa (da frase que salta para fora do texto com ele mesmo e seu exterior) é percebido por Maingueneau mais do que como um novo conceito, mas como algo fundamentalmente constitutivo nos processos de comunicação. Parece-nos, assim como Maingueneau (2005) postulou o primado do interdiscurso, que seria pertinente pensar no primado do destacamento na era da informação predominantemente digital.

Essa reflexão nos levou a pensar em uma relação de simbiose entre os processos de destacamento e a produção/fixação/circulação de memória discursiva. Entendemos que há um risco (de incompreensão) nessa afirmação: a memória discursiva, desde como definida por Pêcheux ou Achard (1999 [1983]), não é um "ponto fixo", um lugar definido onde começa e a partir do qual se expande. Sabemos. Nossa proposta é iniciar uma investigação, a partir da interferência do que chamados de uma "sintaxe do destacamento" (MORAES, 2019a), sobre como os elementos destacados constituem

2 A respeito de tipos de leitura, discorremos em Moraes (2019b). Não se trata de defender um ou outro tipo de leitura, mas de considerar como as características da chamada sociedade digital interferem nos modos de leitura e, consequentemente, de fixação de memória.

3 A expressão alude à refinada discussão sobre a linguagem proposta por Jacqueline AuthierRevuz (AUTHIER-REVUZ, J. (1982) Heterogeneidade(s) enunciativa(s). In: ORLANDI, E. P.; GERALDI, J. W. (org.) Caderno de Estudos Linguísticos. Tradução Celene M. Cruz e João Wanderley Geraldi. Campinas : IEL/Unicamp, v. 19, p. 25-42, jul./dez. 1990). 
aspectos importantes na formação de memória discursiva. Os destaques não são a memória em si, já que, segundo Pêcheux (1999 [1983], p. 50), a memória discursiva deve ser entendida "nos sentidos entrecruzados da memória mítica, da memória social inscrita em práticas, e da memória construída do historiador". O autor explicita:

\begin{abstract}
[...] a memória discursiva seria aquilo que, face a um texto que surge como acontecimento a ler, vem restabelecer os "implícitos" (quer dizer, mais tecnicamente, os pré-construídos, elementos citados e relatados, discursostransversos etc.) de que sua leitura necessita: a condição do legível em relação ao próprio legível. (PÊCHEUX, 1999 [1983], p. 52).
\end{abstract}

Haveria, então, pontos de tensão, de relação, de negociação com a rede de memória preexistente e mesmo a futura. Haverá aspectos que, mesmo destacados, não serão memoráveis, por não serem devidamente enfatizados ou por "falharem" na relação com a rede de memória. Outros poderão se perder com o tempo, por exemplo, na medida em que novas gerações não os "reproduzam/repitam". Não é por acaso que, eventualmente, defrontamo-nos com projetos de reconstrução de memória (sobre a ditadura ou o nazismo, por exemplo). Aqui, ainda, emerge a necessidade de trazer à tona uma reflexão entre a memória discursiva e a memória cognitiva. Tradicionalmente, ao definir a memória discursiva, começa-se por negar a memória entendida como lembrança, que poderia remeter ao caráter individual/psicologista recusado por Pêcheux. Já tendo essa questão como pressuposta e superada (não se trata "apenas" dessa memória), não caberia, no momento atual, pensar em uma relação existente entre a memória discursiva e a cognitiva, que envolveria, inclusive, as ditas "lembranças"? Cremos que não seria impertinente, já que a memória que se impõe no interdiscurso é também memória da qual se lembra (com a qual o cérebro opera), por meio de processos que são também cognitivos, além de interativos etc.

Futuramente, talvez, seja possível delinear melhor essa relação entre memória discursiva e cognitiva. Por ora, remetemos às reflexões de Mussalim sobre a relação entre discurso e cognição. No texto "A dimensão discursiva da cognição ou a dimensão cognitiva do discurso" (MUSSALIM, 2018), a autora se debruça a demonstrar a produtividade da proposta da Neurolinguística de tradição discursiva (ND), conforme postulada/praticada por Maria Irma Hadler Coudry, à luz de um dado que compõe o Banco de Dados em Neurolinguística (BDN). Tal proposta assume os processos discursivos/interacionais como princípio teórico-metodológico de base. A reflexão de Mussalim levou-a a defender a potencialidade da concepção de cognição distribuída (conforme FLOR; HUTCHINS, 1991 apud MUSSALIM), possibilitando-Ihe "perceber a necessidade de propor, para a concepção de cognição distribuída, a incorporação da noção de dispositivo comunicacional (MAINGUENEAU, 2002, 2006, 2015)" (MUSSALIM, 2018, p. 400). 
Segundo Mussalim, a incorporação do conceito de dispositivo comunicacional refina a compreensão da cognição distribuída e vice-versa, ao menos, diz a autora, quando o objetivo é tratar questões de linguagem, como é o caso do trabalho com os afásicos no CCA (Centro de Convivência de Afásicos, sediado no IEL/UNICAMP), cujos dados integram o BDN. O tema é tratado no âmbito da "fecundidade da relação discurso/ (socio)cognição, tão bem sedimentada pela Neurolinguística de tradição discursiva (ND) proposta por Coudry" (MUSSALIM, 2018, p. 402). Mussalim (2018, p. 402) adentra uma questão fundamental para a AD, a das anterioridades, especificamente, "a problemática dos discursos enunciados e sentidos produzidos numa espacialidade e/ou temporalidade anterior à produção de um discurso em questão". Tal problemática emerge em conceitos (fundadores) como os de memória discursiva, interdiscurso, pré-construído e discurso transverso ou ainda, mais recentemente, no que Paveau denominou de pré-discursos.

Interessa ter em mente a recorrente emergência de enunciados formulados antes (em alguma parte...) e retomados em um discurso, consubstanciados como seu pressuposto, uma verdade ou raciocínio previamente admitido, o que Foucault relaciona à constante "retomada de enunciados, que são repetidos, refutados, transformados, denegados" (MUSSALIM, 2018, p. 403). Retomada que é, também, recriação, reinauguração. Ainda conforme Mussalim, também o postulado de Maingueneau (2005) sobre o primado do interdiscurso configura, de certa perspectiva, o interdiscurso como uma anterioridade. Por sua vez, para Paveau, por meio da categoria dos pré-discursos, o foco da abordagem recai sobre o que chama de "determinações pré-linguísticas', isto é, recai sobre dados anteriores à formulação da linguagem" (MUSSALIM, 2018, p. 405). O efeito da abordagem de Paveau é dotar a Análise do Discurso de uma dimensão cognitiva, ainda pouco investigada (e, por isso mesmo, possivelmente, talvez - inconscientemente? - renegada). Esse caminho - aqui brevemente descrito - levou Mussalim a uma problemática sobrejacente, interessando-se por uma potencialização da natureza e da dimensão da competência discursiva, categoria também definida por Maingueneau (2005) e ainda possivelmente pouco explorada. Parece-Ihe, então, que tal categoria, à luz do conceito de pré-discursos de Paveau, mereceria ser reformulada e ampliada,

[...] a fim de que pudesse vir a incorporar um outro tipo de capacidade do enunciador, a saber, a de operar a partir de quadros pré-discursivos coletivos, que têm um papel "instrucional" para a produção e a interpretação dos discursos. A competência discursiva, portanto, passaria a contemplar, minimamente, aspectos de duas naturezas: ideológica e cognitiva. (MUSSALIM, 2018, p. 406).

A noção de cognição distribuída deve ser compreendida no âmbito sistêmico, não apenas no nível cognitivo individual, tendo em vista relações de interação entre sujeitos falantes, ambientes e artefatos. Se a noção de memória discursiva puder ser acrescida de uma dimensão cognitiva, não significaria, da mesma forma, individualizá-la, mas compreendêla, também, "mediante o estudo da representação do conhecimento nas mentes dos 
indivíduos e sua propagação entre indivíduos e artefatos (FLOR; HUTCHINS, 1991)" (MUSSALIM, 2018, p. 407). A memória cognitiva, assim, não seria individual.

Ainda sobre nossa proposta de reavaliar a negação radical da compreensão da memória como imagem/lembrança, remetemos à reflexão (delicada e pertinente, a nosso ver) de Valério e Milano (2019) sobre a singularidade da memória na enunciação de sujeitos idosos. As autoras revisitam a teoria psicanalítica e compreendem a memória como "uma reinauguração de algo vivido, o que contradiz a visão do senso comum acerca da recorrência à repetição nas narrativas de alguém que envelhece" (VALÉRIO; MILANO, 2019, p. 1). Sob a perspectiva linguística-enunciativa, a memória é revelada como "uma possibilidade de percorrer o tempo, permitindo a cada um a continuidade temporal, sem ruptura com o presente, como algo capaz de dar vida nova ao acontecimento e à experiência do acontecimento" (p. 1). Do ponto de vista filosófico, as autoras retomam Ricoeur, para quem "a memória é capaz de potencializar as experiências e de atribuir significados" (VALÉRIO; MILANO, 2019, p. 3), sendo que, para o filósofo, o passado do qual se lembra não é um ponto original, mas um não agora. Quanto ao olhar psicanalítico, as autoras resgatam textos de Freud a partir de Garcia Roza (1991, p. 36 apud VALÉRIO; MILANO, 2019, p. 8), compreendendo a memória como "o poder que uma vivência tem de continuar produzindo efeitos" , podendo remeter a um desejo, inconsciente, de reviver uma experiência. Assim, repetir não é somente recordar, é também resistência (resistir em apreender o próprio tempo!). As autoras concluem que a repetição é constitutiva do sujeito (e não só do sujeito idoso), recusando "o raciocínio simplista de que esse fenômeno é, necessariamente, negativo ou patológico" (p. 12). Acreditamos que essa reflexão sobre a memória, como iminência do lugar de fala do sujeito e resistência em perpetuar o tempo, possa ser, ao menos em parte, integrada a uma concepção de memória discursiva, que é também persistência/resistência sobre um tempo e um discurso, o que passa por filtros de posicionamentos que são, também, inconscientes.

Voltando à relação por nós aqui proposta (entre destacamento e memória), por ora, a vislumbramos (metaforicamente) como uma figura onde cada ponto seja um elemento de destaque. Cada sujeito "estabelecerá memória" ao fazer ligações diferentes entre os pontos, ou seja, a memória terá matizes distintos, não significando que seja individual, mas compartilhada entre grupos, sendo que, por sua vez, cada grupo poderá também ter encontros diferentes com outros. Os pontos são infinitos, como estrelas; também são infinitas as relações possíveis, como galáxias que se interconectassem. As ligações têm relação com o posicionamento do sujeito (envolto por ideologia e inconsciente, como pressupõe a Análise do Discurso) e, também, provavelmente, com o "conhecimento nas mentes dos indivíduos" (MUSSALIM, 2018, p. 407). Vislumbramos, assim, microuniversos de memória. 
Figura 1. Representação imagética da relação entre destacamento e memória

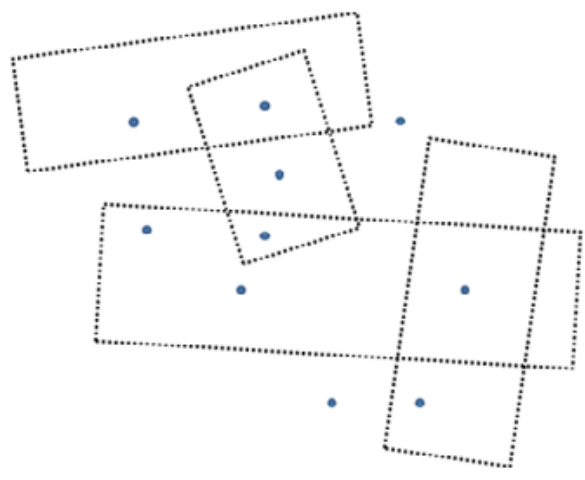

Fonte: Elaborado pela autora

Tais configurações podem estar mudando (acelerando... processos que implicam ganhos e perdas, talvez mais dessas últimas) frente às características da chamada sociedade digital. Neurocientista cognitiva e pesquisadora da leitura, Maryanne Wolf (2019, p. 11) defende que "a passagem de uma cultura baseada no letramento para uma cultura digital difere radicalmente de outras passagens anteriores de uma forma de comunicação para outra". Assim, é pertinente refletir sobre como a cultura digital pode interferir, também, na concepção de memória discursiva. Não se trata de apologia às novas tecnologias. A autora, aliás, denota preocupação em relação ao "modo como a organização dos circuitos do cérebro leitor pode ser alterada pelas características singulares da mídia digital, particularmente nos jovens" (p. 16). Sem incorrer no extremo oposto (o de negar qualquer benefício das novas tecnologias), a autora levanta questionamentos importantes, como o seguinte: a extensiva combinação da leitura em formatos digitais com outras experiências de imersão digital (jogos, mídias sociais, aplicativos) não levaria a impedir "a formação dos processos cognitivos mais demorados, como o pensamento crítico, a reflexão pessoal, a imaginação e a empatia que fazem parte da leitura profunda" (p. 17)? A questão é complexa, mas as pesquisas apontadas pela autora já mostram modificações nas áreas do cérebro solicitadas de acordo com tipos de leitura/interação desenvolvidos. Essa preocupação percorre todo o livro da autora, que procura propor um caminho não dualista, de convivência entre tecnologias digitais sem abrir mão de profundidade de leitura.

Wolf situa a leitura como importante potencializadora e impulsionadora de novas conexões neurais, já que ler não é algo natural ou inato, mas força o cérebro a desenvolver novas e sofisticadas funções por meio de sua plasticidade. O contato com a obra de Wolf estimulou a nossa hipótese de que um (bom) caminho para a convivência dos modos de leitura digital com a reflexão profunda, típica da leitura "tradicional", deva passar por uma reflexão acentuada em torno dos próprios novos modos de leitura. Se pensarmos como eles interferem na solidificação de memória, há também a consequência de que esse próprio processo de reflexão possa levar a teorias enriquecidas sobre a constituição 
de memória na contemporaneidade. É preciso, no entanto, driblar barreiras em nome da criticidade, já que, como diz a autora, "a ilusão de estarmos informados por um dilúvio diário de informações dimensionadas eletronicamente para o olho pode dificultar uma análise crítica de nossas realidades complexas" (WOLF, 2019, p. 20).

As preocupações de Wolf vêm ao encontro da relação inexorável entre midium e discurso. Como explica Mussalim (2018, p. 409),

[...] compreender o dispositivo enquanto uma instância que dispara a enunciação pressupõe a consideração de que a transmissão do texto não vem depois de sua produção e que suas formas de circulação não vêm depois de sua produção e antes de sua recepção; diferentemente, tudo isso se instaura concomitantemente e de maneira integrada, ao se acionarem certos dispositivos comunicacionais, como os gêneros do discurso e o midium, que exercem coerções específicas sobre a enunciação.

A seguir, apresentamos como esses "pontos nodais" se materializam nos destacamentos de notícias em aplicativos, com base em exemplos que trazem em comum o acontecimento da tragédia cultural, humana e ambiental.

\section{Um destacamento reiterado: o acontecimento trágico}

Ao ler notícias sobre o Brasil em veículos estrangeiros, especialmente com a popularização de seus aplicativos, deparamo-nos com uma "imagem escancarada" de nossos problemas. Não é questão, apenas, de considerar as diferenças de abordagens por veículos de diferentes localizações geográficas, mas de contemplar um cruzamento de leituras embasadas por pontos de vista exteriores. Não se trata, portanto, tão somente de analisar nuances de abordagens dirigidas a "leitores-modelo" distintos, mas de valorizar a conexão entre elas. Assim, posicionamo-nos a favor do empoderamento que a leitura de diferentes veículos pode trazer em termos de um tratamento "globalizado" da informação.

Tendo isso em mente, consideramos que o acontecimento jornalístico (que dá visibilidade ao acontecimento "da vida real") é catalisador de memória discursiva. Embora se possa dizer que os processos de edição jornalística sejam decisivos na seleção do que será divulgado, a interação do público interfere nos graus de visibilidade, de modo cada vez mais frequente na era da informação multimidiática digital. É comum, ainda, que se configurem "bolhas de informação", já que as pessoas usualmente trocam conteúdo por meio de suas próprias redes. Nesse viés, defende-se aqui que o acesso à imprensa internacional expande o olhar-leitor, sem desconsiderar que também essa leitura deve ser crítica. 
Tomaremos como exemplo algumas das notícias ${ }^{4}$ sobre o incêndio no Museu Nacional do Rio de Janeiro em setembro de 2018, considerado pela imprensa internacional como uma "tragédia cultural". Uma notícia publicada em Le Monde (figura 2) destaca a previsibilidade da tragédia, associando-a à falta de medidas preventivas, o que é condensado no título: "Incêndio no Museu Nacional do Rio: 'uma parte da tragédia poderia ter sido evitada"'5 (Le Monde, 03/09/18). O subtítulo destaca que "as chamas destruíram um dos mais antigos museus do Brasil", sinalizando, ainda, a existência de "20 milhões de peças de valor", um dado numérico que ajuda a dimensionar a importância do museu em termos de patrimônio histórico e cultural. A figura 3, por sua vez, traz um destacamento em vídeo, com imagens das chamas acompanhadas pelo título "No Brasil, um museu de 200 anos parte em fumaça" (Le Monde, 03/09/18). A predominância da cor laranja, representação fotográfica das próprias chamas, é uma constante das matérias.

Figura 2. Le Monde

\title{
Incendie dans le Musée national de Rio : « Une partie de la tragédie aurait pu être évitée "
}

\author{
Le 3 septembre 2018 à 03 h23 \\ Mis à jour le 3 septembre 2018 à 18 h51
}

Des flammes ont détruit l'un des plus anciens musées du Brésil abritant 20 millions de pièces de valeur.

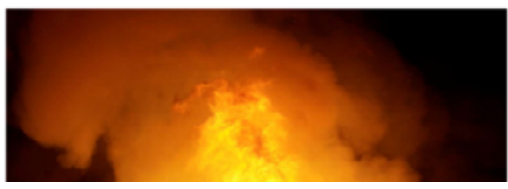

Fonte: Print gerado do aplicativo pela autora

\begin{abstract}
4 Desde 2015, coletamos um corpus de notícias sobre o Brasil no aplicativo Le Monde. Em relação ao corpus do BBC News, agradecemos à coleta da estudante Rafaela Fernanda Thimoteo, bolsista de Iniciação Científica, que desenvolveu a pesquisa "Aplicativos de notícias e efeitos de sentidos: o Brasil em BBC News", sob nossa orientação (Edital 2018 PIBIC-CNPq).
\end{abstract}

$5 \mathrm{~A}$ tradução dos títulos em francês e em inglês são de nossa responsabilidade. 
Figura 3. Le Monde

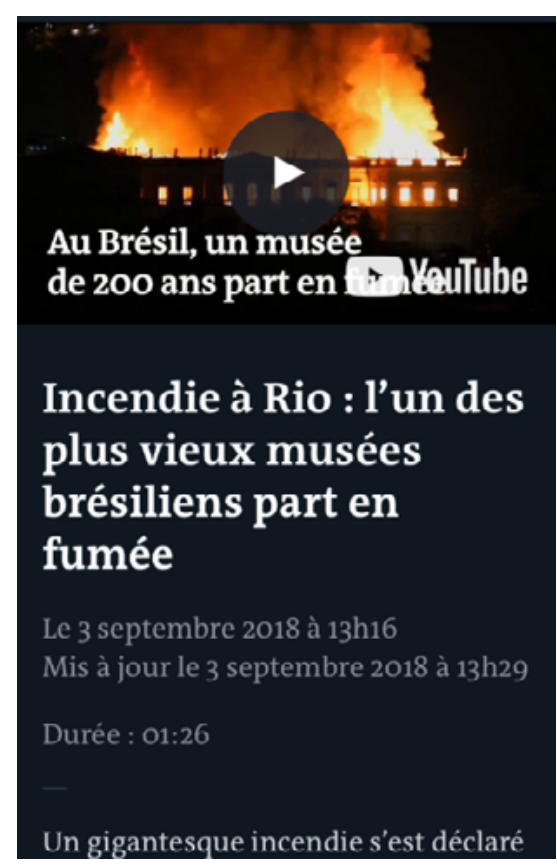

Fonte: Print gerado do aplicativo pela autora

A cor de chamas também predomina na representação visual de outros veículos, como $B B C$ News, que destaca, ainda, a expressão de tristeza das pessoas que assistem à tragédia no país, como se pode ver na figura 4, acompanhada da legenda "A destruição do museu foi descrita como uma tragédia cultural" (BBC News, 3/9/18). A imagem em destaque simboliza bem o efeito de sentido de que não há mais o que fazer, além de lamentar, já que a tragédia já aconteceu, dialogando, de certa forma, com a abordagem de Le Monde, segundo a qual há necessidade de prevenção para evitar esse tipo de acontecimento trágico: não tendo havido prevenção (por parte de autoridades), resta o lamento (da população). O veículo BBC News traz ainda, em 3/9/18, o seguinte título: "A stark metaphor for a city in crisis" (Uma metáfora gritante para uma cidade em crise), com o destaque: "This isn't just Brazilian history that's gone up in flames. Many see this as a metaphor for the city - and the country as a whole" ("Não é apenas a história brasileira que cai em chamas. Muitos veem isso como metáfora de uma cidade - e de um país como um todo").

Interdiscursivamente, é possível retomar uma matéria de 2016 publicada em Le Monde com o título "Au Brésil, l'Etat de Rio ne répond plus" (No Brasil, o Estado do Rio não responde mais), que faz parte do material analisado em Moraes (2019a), onde predomina o efeito de sentido de algo sem solução, em associação a um problema recorrente e avançado em consequências (no caso, a crise econômica). 
Figura 4. BBC News

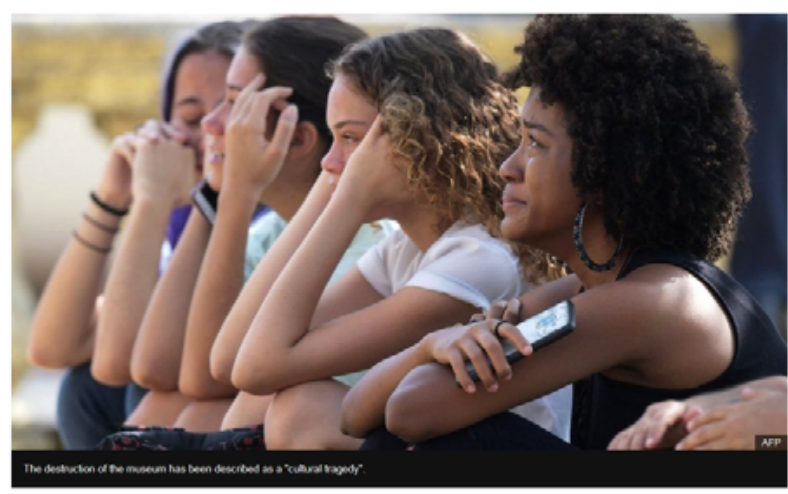

Fonte: Imagem gerada do site BBC News pela autora

A matéria a seguir (Figura 5), de Le Monde, por sua vez, traz uma comparação entre Brasil e França, condensada no título: "Incêndio no Museu do Rio: impossível na França, 'a segurança é bem melhor"' (Le Monde, 4/9/18), onde o trecho entre aspas corresponde à citação de fonte ouvida pelo jornal, Bruno David, Presidente do Museu Nacional de História Natural em Paris. A cor laranja das chamas é substituída pelo vazio do museu, cujo teto desabou.

Figura 5. Le Monde

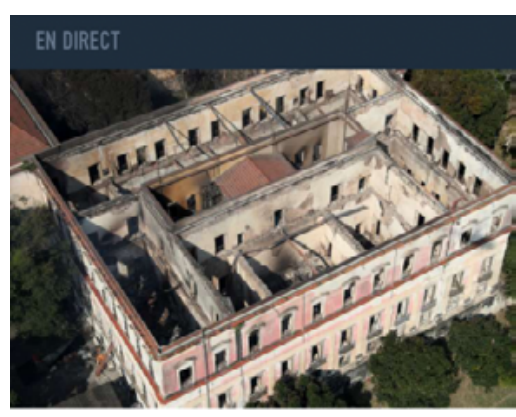

Incendie du Musée de Rio : impossible en France, " la sécurité est bien meilleure " SÉLEETION DE LA RÉDACTION

$$
\begin{aligned}
& \text { La "voie classique " vers } \\
& \text { le mont Blanc bientôt } \\
& \text { soumise à des quotas } \\
& \text { Le typhon Jebi, le plus puissant à } \\
& \text { atteindre le Japon " depuis } 1993 \text { " }
\end{aligned}
$$

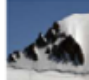

Fonte: Print gerado do aplicativo pela autora 
É produzido o efeito de certo excesso de confiança no último título francês, pautado na memória de que o Brasil é, tipicamente, mais suscetível a tragédias ocasionadas por falta de manutenção em comparação a países desenvolvidos, como os europeus. Ainda que se possa afirmar que a França seja menos suscetível a esse tipo de tragédia relacionada à falta de manutenção, a palavra "impossível" é muito forte, e foi posta em prova pelo incêndio de grandes proporções na Catedral de Notre Dame, ocorrido em abril de 2019.

Infelizmente para o Brasil, outros acontecimentos trágicos contribuem para corroborar cada um deles como metáfora de um país em crise (estrutural, política, econômica, ambiental etc.). No mesmo setembro de 2018, Le Monde noticia com grande destaque a morte do Rio Doce, com os títulos: "O Rio Doce: rio jovem, rio morto..." (vídeo) (Le Monde, 4/9/18) e "No Brasil, a bolha tóxica matou o Rio Doce" (reportagem) (Le Monde, 4/9/18). As abordagens retomam o acidente com a barragem de Mariana em 2015 que, além de perdas humanas, provocou desequilíbrio ambiental.

Figura 6. Le Monde

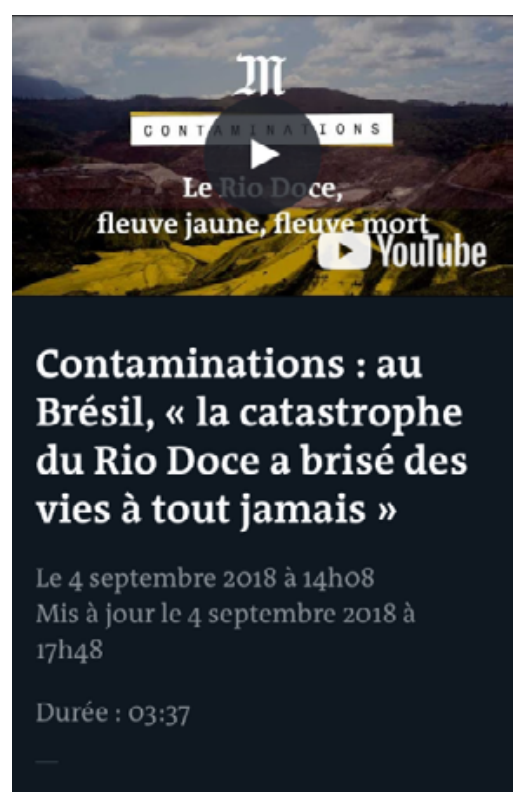

Fonte: Print gerado do aplicativo pela autora 
Figura 7. Le Monde

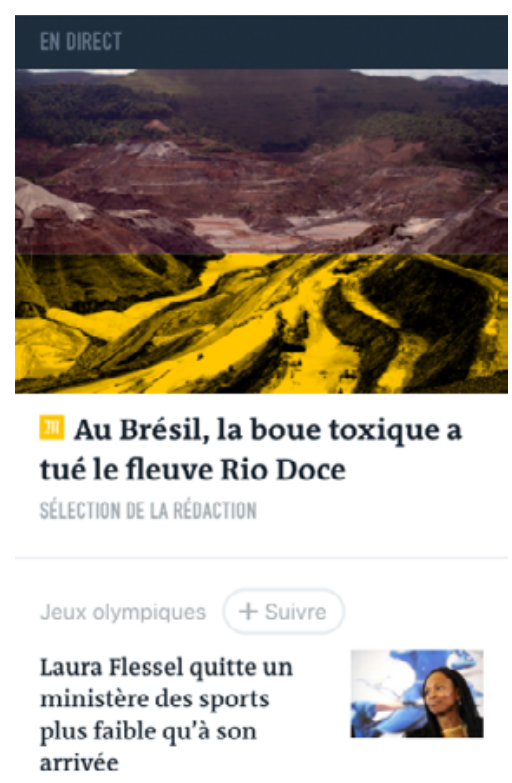

Fonte: Print gerado do aplicativo pela autora

A tragédia em nosso país é repetida em janeiro de 2019, com o acidente da barragem de Brumadinho, de responsabilidade da empresa Vale, da mesma forma que o acidente anterior em Mariana, ambas em Minas Gerais. Há inúmeros trabalhos que põem em xeque a natureza da eficácia jornalística, uma vez que, sabemos, é a própria construção discursiva de seus critérios e de sua deontologia que legitimam a sua prática (RINGOOT, 2014). No entanto, por mais que o jornalismo, também ele, enfrente suas crises de legitimidade, por mais que o bordão de que "os fatos falam por si" seja discursivamente questionável, a recorrência de acontecimentos trágicos não é mera opção editorial jornalística (embora suas formas de destacamento possam ser). 0 tom e a cor das tragédias (representadas pelo laranja das chamas ou pela lama das barragens) não são mera angulação, é também retrato de acontecimentos-acontecimentos, que não são meras metáforas de estilo para quem perde suas vidas repentinamente em uma tragédia ou, paulatinamente, em consequência de problemas de natureza ambiental. Assim, memória é construção discursiva, mas também retrato do que de fato ocorre, pelo menos em boa parte das vezes.

Sem negar o acontecimento, entendemos que a forma como ele é destacado (e, consequentemente, fixa-se como memória) tem relação com processos de edição e circulação. Assim, pode-se perceber que, na circulação internacional, o acontecimento da tragédia circula (e fixa-se) menos como fatalidade do que como desleixo, relacionandose a uma imagem mais geral do Brasil como a de um país subdesenvolvido, relapso com sua história e seu meio ambiente, indiferente ao patrimônio cultural e mesmo a vidas humanas. O descuido (ou a fatalidade) não é exclusividade brasileira (vide incêndio 
em Notre Dame), mas a reincidência fortalece a relação entre circulação e imagem, o ethos de um país que se configura. O estatuto das tragédias associadas ao Brasil (incêndio, acidentes com barragens, desmatamento) é tipicamente compreendido como acontecimentos que poderiam ser evitados por meio de políticas públicas internas, supostamente, diferente de acontecimentos que envolvem o contato com culturas exteriores (o terrorismo associado ao extremismo islâmico, por exemplo).

Em contrapartida, há no Brasil a circulação de discursos que minimizam o impacto de acidentes ambientais. Qual é a "verdade", com toda a carga filosófica que este termo carrega? Não é fácil dizer, mas acreditamos que a exposição do olhar-leitor ao cruzamento de diferentes abordagens possa contribuir para compreender os acontecimentos tanto como construção discursiva como, ao menos em alguma medida, como correspondentes aos "fatos em si". Para um autor/leitor francês, por exemplo, o relapso do Brasil é tido como mais previsível do que para nós mesmos. Podemos ponderar a visão do outro: nem tomá-la como verdade absoluta, nem descartá-la.

É preciso assumir posição em contraposição à aceitação de "qualquer verdade". Assim, convém compreender, com Angermuller (2018), que a concepção da "verdade na era da pós-verdade" exija um "Programa Forte em Estudos do Discurso", que possa dar conta de uma posição mais próxima de uma verdade técnica, fundamentada, criteriosa. Para Wolf (2019, p. 72), "chegar à verdade das coisas - seja na ciência, na vida ou no texto exige observação, hipóteses e predições baseadas na inferência e na dedução, testagem e avaliação, interpretação e conclusão e, sempre que possível, novas provas dessas conclusões com base em sua replicação". Tal habilidade depende da leitura crítica que é adquirida com a prática da leitura profunda, características que concorrem hoje com a leitura acelerada nas plataformas digitais. A sobrevivência da leitura crítica é inquietante, já que se trata, como diz a autora, de uma habilidade que precisa ser constantemente treinada:

Somente se trabalharmos continuamente para desenvolver e usar nossas complexas aptidões analógicas e inferenciais, as redes neurais que estão em sua base sustentarão nossa capacidade de sermos analistas ponderados e criteriosos do conhecimento, e não apenas consumidores passivos da informação. (WOLF, 2019, p. 76).

Passamos tanto tempo criticando os manuais de jornalismo, por defenderem (às vezes, ingenuamente) a importância de deixar os fatos falarem por si, enquanto nós (os teóricos) entendemos que há angulações, ideologias, posicionamentos. Superado isso, poderíamos caminhar adiante, compreendendo que há relações entre fatos e discursos, sendo que a chave está na habilidade da leitura crítica (WOLF, 2019). A leitura profunda precisa conviver com as novas características da leitura na sociedade digital, quando "processamos a informação o mais rapidamente possível; mais precisamente, lemos mais 
em espasmos menores" (WOLF, 2019, p. 93). Wolf (2019, p. 94) menciona a conclusão de Liu, pesquisador da leitura e da informação: "o 'novo normal' em nossa leitura digital é 'ler por cima"'. Trata-se, portanto, de um modo de leitura que maximiza os efeitos do destacamento.

Com base na leitura crítica, precisamos compreender que, sim, há necessidade de tomar posição (não há neutralidade), mas com base em critérios, não em suposições. A observação de fatos não é o único critério, nem por isso deixa de ser um dos critérios importantes. Há distorções, desinformação, mas também há algo de observável, ainda que afetado por diversos filtros (ideológicos, inconscientes...). Que o leitor se sinta estimulado a aprofundar a partir daquilo que é destacado é um desafio que a sociedade precisa percorrer, sem desconsiderar que a interferência dessa sintaxe do destacamento é algo incontornável.

Ao recapitularmos nossa representação imagética (Figura 1), percebemos aspectos centrais do discurso (incêndio, catástrofe, contaminação, morte do rio... tragédia, tragédia cultural, tragédia ambiental, tragédia humana, descaso, falta de políticas de prevenção... - além de signos não verbais como as cores do fogo ou da lama) que assumem o lugar dos "pontos" que se conectam nas redes de memória. Esses pontos se conectam em micro-redes, influenciadas pelas características do midium (cujo atrelamento às tecnologias digitais potencializa o destacamento), do gênero do discurso (jornalístico, pactuado com a construção de verdades) e também de interações discursivas e cognitivas entre produtores e usuários, cujos resultados dependem de competência discursiva. Consideramos, assim, a pertinência da proposta de Mussalim (2018) sobre a dimensão discursiva da cognição ou a dimensão cognitiva do discurso também para o caso aqui proposto, em que pontuamos a influência de uma sintaxe do destacamento nos processos constitutivos de memória. Enquanto, no recorte aqui apresentado, certos elementos se ressaltam, da mesma forma, em outros recortes, outra realidade será constituída. Se o jornalismo tem o potencial de recortar realidades, ao menos podemos dizer, sem idealizá-lo, que o faz respaldado por critérios relacionados a uma ética profissional e à evidência empírica - cabe ao público, por meio da leitura crítica, elaborar um cruzamento de dados e das informações apresentadas, verificando suas fontes, intenções e interesses correlatos etc. Não queremos aqui endeusar o jornalismo, apenas ressaltar o outro lado do espelho: o das informações que circulam sem critérios, sem compromissos, sem divulgação de fontes, pautadas em interesses diversos e na retórica que constrói as chamadas fake news, disseminadas em escala por redes sociais, em contraponto ao jornalismo criterioso, ainda que sujeito a falhas.

\section{Considerações finais}

Como vimos, Pêcheux inscreveu a memória discursiva nos sentidos entrecruzados da memória mítica, da memória social, da memória construída do historiador... Na faceta 
mítica da memória, as tragédias brasileiras poderiam ser vistas como penitência imposta a um país desleixado, ao modo do discurso bíblico. Na faceta social ou histórica, podem ser associadas à falta de iniciativas públicas de prevenção.

Neste trabalho, propusemos que a sintaxe do destacamento seja um elemento decisivo na discursividade contemporânea, estabelecendo a possibilidade de relações entre o funcionamento do destacamento e a potencialização da memória discursiva. 0 destacamento, em certa medida, é uma tentativa de fechar aquilo que é aberto, mas escapa. Ou seja, tenta condensar o que seriam os aspectos centrais de discursos e, justamente porque discursos não são homogêneos, mas perpassados por posicionamentos mais ou menos inconscientes, as tentativas de apreendê-lo falham e expressam, simultaneamente. Falham não por "erro de processamento", mas porque as falhas são constitutivas da incompletude, do impalpável do discurso. Expressam, porque, nas falhas, apontam pontos observáveis, constatáveis, apesar de tudo (do simbólico inerente ao discurso).

Defendemos que os elementos de destaque influenciam decisivamente: no tratamento da notícia, que pode ser ordinário ou alternativo, conforme Ringoot; na fixação de memória discursiva (na constituição dos microuniversos de memória); na cristalização de sentidos na discursividade contemporânea. O leitor/internauta, por sua vez, terá a leitura influenciada pelos destacamentos, mas também construirá suas próprias novas relações, com base em sua memória, em todos os sentidos aqui discutidos. É premente que não abra mão da leitura profunda e crítica. Quanto mais preparado estiver esse leitor, quanto mais estimulado por processos de leituras, quanto maior for sua rede de memória, mais empoderado para atuar nas conexões de sentidos.

\section{REFERÊNCIAS}

ACHARD, P. Memória e produção discursiva do sentido. In: ACHARD, P. e outros. Papel da Memória. Campinas: Editora Pontes, 1999 [1983]. p. 11-17.

ANGERMULLER, J. Truth after post-truth: for a Strong Programme in Discourse Studies. Palgrave Communications. London: Nature, v. 4, Article number: 30, 2018. Disponível em: https://www.nature.com/articles/s41599-018-0080-1. Acesso em: 4 maio 2018.

MAINGUENEAU, D. Frases sem texto. São Paulo: Parábola, 2014.

MAINGUENEAU, D. Cenas da Enunciação. Organizado por S. Possenti e M. C. Pérez de Souza-e-Silva. Curitiba: Criar Edições, 2006.

MAINGUENEAU, D. Gênese dos Discursos. Tradução Sírio Possenti. Curitiba: Criar Edições, 2005. 
MORAES, É. de. Aplicativos de notícias, destacamento e efeitos de sentido Representações internacionais sobre o Brasil (em UOL e Le Monde). São Paulo: Editora UNESP, 2019a. (Resultado de pesquisa financiada pela FAPESP - processo $n^{\circ}$ 2016/18915-3)

MORAES, É de. O Brasil no aplicativo Le Monde: reflexões sobre uma sintaxe discursiva do destacamento. Revista Calidoscópio, v. 17, n. 3, p. 453-474 set.-nov. 2019b. DOI: 10.4013/cld.2019.173.03.

MORAES, É. de. O destacamento em aplicativos de notícias e a produção de memória discursiva. Revista E-Compós, v. 21, n. 3, ID 1442, 2018. DOI: https://doi.org/10.30962/ ec. 1442 .

MUSSALIM, F. A dimensão discursiva da cognição ou a dimensão cognitiva do discurso. Caderno de Estudos Linguísticos, Campinas, v. 60, n. 2, p. 400-413, 2018.

PÊCHEUX, M. Papel da Memória. In: ACHARD, P. e outros. Papel da Memória. Campinas: Editora Pontes, 1999 [1983]. p. 49-57.

POSSENTI, S. Apresentação. In: MAINGUENEAU, D. Frases sem texto. São Paulo: Parábola, 2014. p. 7-8.

RINGOOT, R. Analyser le discours de presse. Paris: Armand Colin, 2014.

VALÉRIO, P. da S.; MILANO, L. E. Quando repetir é enunciar: questões sobre linguagem e memória. Caderno de Estudos Linguísticos, v. 61, p. 1-15, e019018, 2019.

WOLF, M. O cérebro no mundo digital - os desafios da leitura na nossa era. Tradução Rodolfo Ilari e Mayumi Ilari. São Paulo: Editora Contexto, 2019. 